\title{
La Autonomía de las Entidades Federativas
}

Héctor Guillermo Campbell Araujo ${ }^{61}$

\section{Resumen}

Del análisis de los artículos de la Constitución relativos al federalismo se colige que en México, resulta más adecuado hablar de "autonomía" de los estados integrantes de la federación que del eufemismo "soberanía interior"; dado que el Federalismo es en sí mismo una forma de descentralización de la actividad Estatal o política, necesaria para su propia existencia y la manera de hacer operativa dicha descentralización es darle autonomía a los Estados Federalizados, para que de esta manera les resulte atractiva su integración al Estado Federal.

\begin{abstract}
From the analysis of the articles of the Constitution relating to federalism be inferred that in Mexico, it is more appropriate to speak of State's 'autonomy' of the Federation better than the euphemism "internal sovereignty"; given that federalism is in itself a form of decentralization of State activity or policy, necessary for its own existence and the way to do operative such decentralization, giving autonomy to the States, makes attractive for them their integration to the Federal State.
\end{abstract}

\section{Sumario: I.Introducción. II. Diferencias entre autonomía y soberanía. III. Corolario. IV. Bibliohemerografía}

\section{Introducción}

La Federación surge de la voluntad de varios Estados de unirse, en ese sentido el artículo 40 constitucional, precisa que la República Mexicana se integra por “Estados libres y soberanos en todo lo concerniente a su régimen interior, pero unidos en una federación establecida según los principios de esta ley fundamental". 
Sin embargo esa soberanía de las entidades federativas, en cuanto a su régimen interior, se encuentra acotada por diversos artículos constitucionales, así: E Congreso de la Unión puede admitir nuevos estados en la Federación según el artículo 73; también el mismo precepto permitir afectar a los integrantes actuales de la Federación para generar nuevos estados dentro de los existentes, lo que le corresponde al Constituyente Permanente; el artículo 76 se refiere a la injerencia del Senado en las entidades federativas; en los artículos 103, 105 y 107 el Poder Judicial Federal conoce de Acciones de Inconstitucionalidad, Controversias de Constitucionalidad, Conflictos de Limites Interestatales por medio de La Suprema Corte de Justicia de la Nación; el artículo 115 se refiere al ámbito municipal con exclusión del de la entidad federativa, el 116 a la forma de gobierno que deben adoptar; los diversos 117 y 118 relativo a lo que les está prohibido; la garantía federal consagrada en el 119; en el artículo 122 las Bases para el Distrito Federal, y; en el artículo 124 lo relativo al reparto competencial entre el Poder Federal y el de las entidades federativas.

Por ello se considera más propio hablar de la autonomía de los estados integrantes de la federación que del eufemismo "soberanía interior"; en efecto el Federalismo es en sí mismo una forma de descentralización de la actividad Estatal o política, necesaria para su propia existencia y la manera de hacer operativa dicha descentralización es darle autonomía a los Estados Federalizados, para que de esta manera les resulte atractiva su integración al Estado Federal.

Los juristas Jorge Carpizo y Jorge Madrazo, ${ }^{62}$ sostienen que de la lectura del artículo 40, se puede advertir que dicho precepto se asienta en la teoría de Tocqueville de la cosoberanía: tanto la federación como los estados miembros son soberanos. Sin embargo, manifiestan dichos tratadistas, no obstante que al parecer el artículo precitado se encuentra en contradicción con el artículo 39 constitucional que sostiene que la soberanía es popular; afirman que de una interpretación integral conjuntando los artículos 39, soberanía popular; 40 
soberanía interior de los estados, y; 41 el ejercicio de la soberanía popular a través de los Poderes de la Unión en su competencia y por los de los Estados en sus regímenes interiores en los términos establecidos por la Constitución Federal y las particulares de los Estados, que no pueden contravenir el pacto federal.

De esta interpretación se advierte que las entidades federativas son autónomas, que existe una división de competencia entre los dos órdenes (no niveles que ninguno es superior y por tanto el otro inferior) que la propia Constitución Federal crea y que están subordinados a ésta, que establece la descentralización política.

Señalan, además los autores citados, que el Estado Federal mexicano se sustenta en los principios de:

a) Las entidades federativas son instancia decisoria suprema dentro de su competencia (artículo 40)

b) Entre la federación y las entidades federativas existe coincidencia de decisiones fundamentales(artículos 40 y 115)

c) Las entidades federativas se dan libremente su propia Constitución en la que organizan su estructura de gobierno, pero sin contravenir el pacto federal inscrito en la Constitución general, que es la unidad del pacto federal (artículo 41)

d) Existe una clara y diáfana división de competencia entre la federación y las entidades federativas: todo aquello que no esté expresamente atribuido a la federación es competencia de las entidades federativas (artículo 124) ${ }^{63}$

Luego entonces dentro del Estado Federal el orden jurídico se compone por una doble estructura con un ámbito espacial y temporal de coexistencia integrado por normas centrales válidas en todo el territorio y normas locales válidas solamente en parte del territorio; evidentemente las normas centrales son las federales creadas por el órgano legislativo central (Congreso de la Unión) mientras que las 
normas locales son creadas por los órganos legislativos de los Estados-miembros (Congresos de los Estados).

El ámbito material de validez del orden jurídico, en un Estado-Federal, es decir la competencia de su legislación se encuentra dividida entre varias autoridades locales y una sola central.

En la medida en que los miembros de la Federación, están facultados para darse su propio estatuto, se puede definir la autonomía como la competencia de la que gozan los Estados miembros para darse sus propias normas, que se inician y derivan de su propio estatuto local.

Ignacio Burgoa ${ }^{64}$ denomina "la órbita autárquica de los Estados", a la que la caracteriza y comprende las siguientes materias:

a) La constitucional, en cuanto que pueden darse sus propias constituciones conforme a los principios establecidos en la Constitución General de los Estados Unidos Mexicanos.

b) Democrática, en el sentido de poder elegir o nombrar sus órganos de gobierno.

c) Legislativa, expedir leyes de su competencia, estimando como tales las que no competen expresamente al Congreso de la Unión o contrarias a las prohibiciones impuestas por la Constitución Federal a los Estados integrantes de la Federación o las obligaciones estatales consignadas en ellas.

d) Administrativa, en las diferentes ramas de su gobierno interno la aplicación o ejecución de su propia legislación.

e) Judicial, para que los conflictos jurídicos sean dirimidos por los órganos locales en los casos que no sean de expresa competencia federal.

Con rigor técnico algunos autores señalan que propiamente no se debe hablar de Constitución Local sino de Estatuto Legal, tal como se hace al referirse el artículo 
122 al instrumento que rige el Distrito Federal, por que sostienen que en el Estado Federal mexicano existe una sola Constitución la Federal, con el carácter de suprema y depositaria de la soberanía, y por tanto las de los estados miembros no pueden tener esta denominación ya que emanan, derivan y están acotadas por aquella, así en estos instrumentos se deposita autonomía y no soberanía y estatuye en los términos y con los límites que la primera le ordena. ${ }^{65}$

\section{Diferencias entre autonomía y soberanía}

La soberanía y la autonomía se traducen en un orden jurídico, sin embargo la diferencia es que en el estado autónomo existen una voluntad ajena que le impone limitaciones jurídicas que deben observarse y condicionan o determinan el contenido y el sentido de sus decisiones primordiales; lo que no sucede en el estado soberano. Elisur Arteaga ${ }^{66}$ considera inapropiado la referencia constitucional a los estados miembros como soberanos, porque no es correcto llamarlos así si su funcionamiento y organización está supeditado a alguien superior por lo que lo correcto es llamarlos autónomos y su campo de acción autonomía.

Así en cuanto a la forma de gobierno las entidades federativas tienen la obligación de adoptar para su régimen interior la forma de gobierno republicano, representativo y popular y al Municipio como base tanto de su división territorial y organización política. La carta magna también precisa las bases de organización de los poderes locales. ${ }^{67}$

Los estatutos legales deberán apegarse a lo anterior y en su parte orgánica establecen la forma de gobierno y se crean $y$ organizan $y$ distribuyen competencias del gobierno local, legislando a través de sus órganos y la aplican, siendo tal como lo señalan Carpizo y Madrazo instancias decisorias. La mayoría de ellos establece el principio de división de poderes de manera semejante a la formula federal. 
La Constitución General establece prohibiciones y obligaciones positivas para las entidades federativas ${ }^{68}$; las primeras clasificadas como absolutas (que en ningun caso pueden ejercerse) y relativas (que con el consentimiento del Congreso de la Unión pueden ejercerse) y que se les prohíben en ambas casos por ser facultades expresas de la federación y solo en situaciones extraordinarias, en el caso de las relativas, se delegan a los estados miembros. La obligación positiva de entregar/extraditar a los reos; de dar fe y crédito a los actos y registros y procedimientos de todas las entidades federativas; ejecutar las resoluciones.

El Congreso de la Unión tiene injerencia en las reformas al territorio nacional ${ }^{69}$, sí se trata de admitir nuevas entidades federativas, se ignora la voluntad puesto que no se requiere ni la opinión de las entidades federativas y basta la decisión de la legislatura; para formar nuevos estados dentro de los límites de los ya existentes se escucha la opinión de los afectados pero no obliga y quien tomará la determinación será el Poder Reformador que se conforma con la aprobación que del Congreso de la Unión y la Legislatura de los Estados.

El Senado de la República hace la declaratoria de desaparición de poderes locales cuando se realizan los supuestos previstos y sí el estatuto legal no prevee la situación nombrar a la autoridad local; así como intervenir en los asuntos internos a solicitud de la entidad federativa o de oficio en situaciones violentas ${ }^{70}$.

La teoría federal sostiene que los estados miembros renunciaron a su soberanía a cambio de la protección que reciban, esta situación es lo que se conoce como "garantía federal" y que se traduce en la obligación de los poderes de la unión de proteger a los Estados contra toda invasión o violencia exterior y a solicitud de la entidad federativa en caso de sublevación o trastorno interior, ${ }^{71}$

Las entidades federativas también a cambio de su integración y aportación al pacto federal, deben participar en la voluntad federal, lo que hacen al formar parte, por medio de las Legislaturas locales, del Poder Reformador previsto en el artículo 135 Constitucional. Con este sistema de reformas, en el que las entidades 
federativas participan, se refiere a generación de normas constitucionales relativas evidentemente al Estado Federal Mexicano y su orden jurídico.

Hay quienes sostienen que también participan por medio del Senado pero creemos que los legisladores son representantes de la nación y no de los estados miembros, toda vez que no hay una obligación vinculatoria entre sus decisiones y las de las entidades federativas; aunado a lo anterior la presencia de senadores plurinominales desvirtúa dicha tesis, toda vez que este $25 \%$ del Senado no representa específicamente a entidad federativa alguna; además el Senado de manera general participa en el proceso legislativo ordinario federal, y no en asuntos referidos al Estado Federal.

\section{A manera de conclusión}

En México, resulta más adecuado hablar de "autonomía" de los estados integrantes de la federación que del eufemismo "soberanía interior"; dado que el Federalismo es en sí mismo una forma de descentralización de la actividad Estatal o política, necesaria para su propia existencia y la manera de hacer operativa dicha descentralización es darle autonomía a los Estados Federalizados, para que de esta manera les resulte atractiva su integración al Estado Federal. 